\section{ВЛИЯНИЕ РЕФОРМЫ БЮДЖЕТНОГО ЗАКОНОДАТЕЛЬСТВА НА ФИНАНСОВОЕ ОБЕСПЕЧЕНИЕ ОРГАНОВ МЕСТНОГО САМОУПРАВЛЕНИЯ: СРАВНИТЕЛЬНАЯ ХАРАКТЕРИСТИКА БК РФ ОТ 31.07.1998 Г. И ПРОЕКТА НОВОГО БК РФ}

\section{Аннотация:}

Статья посвящена реформированию бюджетного законодательства финансовой деятельности органов местного самоуправления. Предметом изучения выступили положения действующего Бюджетного кодекса РФ, а также нормы проекта нового БК РФ, содержащие разные аспекты бюджетных полномочий местных органов. Цель исследования соcтоит в сравнении нормативно-правовых актов, выявлении недостатков существующего законодательства, а также устранении законодательных пробелов. Анализ действующего БК РФ и проекта нового БК РФ позволил сделать следующие выводы: реформы бюджетного законодательства не приведут к существенным изменениям в финансовой деятельности органов местной власти. Omсутствие детального регулирования критериев выделения бюджетных средств на местный уровень обусловливает расиирение бюджетных прав субъектов в отношении муниципалитетов. В настоящее время местные бюджеты испытывают острую зависимость от бюджетов федерального центра и соответствующего региона Необходимо признать, что проект нового БК РФ далек от совершенства, поскольку не отражает всех бюджетных реалий. Между тем развитие федеративного государства возможно только в случае создания в нашей стране подлинно действующего законодательства во всех областях жизнедеятельности общества, в первую очередь в бюджетной сфере, которое отвечает всем требованиям современной действительности.

Ключевые слова:

реформы бюджетного законодательства, межбюджетные трансферты, бюджетные полномочия органов местного самоуправления, резервный фонд, бюджетные расходы, восстановление платежеспособности, муниципальный финансовый контроль, показатели кредитоспособности, распределение доходов от итрафов.
Kazan (Volga Region) Federal University

\section{THE INFLUENCE OF THE REFORM OF BUDGETARY LEGISLATION ON THE FINANCIAL SUPPORT OF THE LOCAL GOVERNMENT AUTHORITY: A COMPARATIVE ANALYSIS OF THE BUDGET CODE OF THE RUSSIAN FEDERATION AS OF 31.07.1998 AND ITS NEW DRAFT}

Summary

The article is devoted to reforming the budgetary legislation of financial activity of local government authority. The study focuses on the provisions of the current Budget Code of the Russian Federation including its new draft standards covering various aspects of the budgetary power of local bodies. The research objective is to compare laws and regulations, identify shortcomings in existing legislation, and eliminate legislative gaps. Analysis of the current Budget Code of the Russian Federation and its new draft allowed the author to draw the following conclusions: the reforms of the budgetary legislation will not cause the significant changes in the financial activities of local authorities. The lack of detailed regulation of the criteria for allocating budget funds to the local level leads to enhancing the budgetary rights of the subjects in relation to municipalities. Nowadays, local budgets are highly dependent on the budget of the federal center and the budget of the region. It must be recognized that the draft of the new Budget Code of the Russian Federation is far from perfect since it does not reflect all budgetary realities. Meanwhile, the development of the Russian federal state is possible only when creating a genuinely effective legislation in all areas of society, primarily in the budgetary sphere which meets all the requirements of modern reality.

Keywords reform of budgetary legislation, inter-budgetary transfers, budgetary powers of local government authority, reserve fund, budgetary expenditures, solvency restoration, municipal financial control, credit ratings, distribution of fines income.

В начале мая 2015 г. Минфин РФ разработал проект нового Бюджетного кодекса Российской Федерации (далее - проект БК РФ) [1]. Данный документ должен заменить ныне действующий Бюджетный кодекс Российской Федерации (далее - БК РФ) [2], который был принят в 1998 г. При этом, как отмечает Н.А. Поветкина, «разработка новой редакции Бюджетного кодекса происходит в непростое время для нашего государства, что является несомненным позитивным моментом, поскольку именно под действием рисков, угроз, разных кризисных явлений, пройдя "дополнительную проверку", можно говорить о качестве того или иного нормативного акта, в том 
числе Бюджетного кодекса, его способности предусмотреть и урегулировать различные "внештатные" ситуации и выполнить цели и задачи, стоящие перед ним» [3, с. 159].

Основными целями подготовки законопроекта являются консолидация бюджетного законодательства, придание ему системности, стабильности, а также реализация новаций. Поставленные цели оправданны, так как с момента принятия действующего БК РФ в силу вступили более 100 федеральных законов о многочисленных поправках к нему. Одновременно предполагается внести изменения и в иные нормативно-правовые акты, отражающие разные аспекты финансового обеспечения органов местного самоуправления (например, в законодательство об административных и налоговых правонарушениях).

Предлагается совершенно новая структура документа, включающая 9 разделов, 33 главы и 313 статей. Деление БК РФ на части разработчики проекта признали нецелесообразным. Одновременно со структурой меняется и терминология. В проект были включены следующие новые понятия: «получатель средств из бюджета» (п. 30 ст. 5 проекта), «лимит долгосрочных контрактных обязательств» (п. 35 ст. 5), «временно свободные средства» (п. 43 ст. 5) и др. Подверглась расширению категория бюджетной системы Российской Федерации за счет включения в нее участников бюджетного процесса (п. 3 ст. 5). Вместе с тем термин «структура бюджетной системы» исчез из проекта БК РФ. Также удалены такие категории, как "собственные доходы», «межбюджетные отношения», «бюджетная роспись» и т. д.

В то же время заметим, что понятия и термины, закрепленные в ст. 5 проекта, нуждаются в дальнейшей доработке и совершенствовании (например, «правоотношения», «бюджет», «бюджетный процесс»). Как отмечается в литературе, «в проекте отсутствует детальная проработка терминологии, используемой при регулировании доходов бюджета:

- согласно ст. 5 проекта доходы бюджета - поступающие в бюджет денежные средства;

- в ст. 34 в качестве доходов перечисляются разнородные категории, большинство из которых не являются денежными средствами и не соответствуют определению дохода;

- из ст. 35 следует, что под доходами следует понимать налоги и сборы (что прямо противоречит налоговому законодательству), штрафы (что противоречит уголовному и административному законодательству, которые относят штрафы к видам наказаний) и т. д.;

- по существу доходы бюджета являются источниками покрытия расходов бюджета. В проекте используется близкий к этому термин "источники финансирования бюджета", но из ст. 5 следует, что источники фринансирования бюджета не являются доходами бюджета, что создает смысловое противоречие» [4].

Представляется, что для устранения имеющегося противоречия необходимо в ст. 5 проекта закрепить понятие «источник дохода», в качестве которого предусмотреть произведенные и непроизведенные предметы материального мира, в том числе национальные богатства. В целом мы считаем, что наличие терминологических противоречий в тексте проекта отражает не только отсутствие детального анализа законодателем предшествующего опыта использования обозначенных понятий, но и игнорирование научных наработок по исследуемым вопросам. Как справедливо отмечают О.Н. Горбунова, Х.В. Пешкова и Т.А. Вершило, «недостаточное внимание российских нормотворческих органов к выводам финансово-правовой науки при разработке законопроектов снижает качество их содержания и негативно сказывается на финансовой практике» [5, с. 39].

Важное нововведение проекта - появление новой главы «Информационное обеспечение в сфере бюджетных правоотношений», где намечается создание единого портала бюджетной системы РФ. Минфин России предлагает пересмотреть и дополнить некоторые принципы бюджетной системы РФ. В ныне действующем БК РФ им отведена специальная глава 5, в проекте принципы закреплены в гл. 3 «Основы бюджетной системы Российской Федерации». В проекте БК РФ принцип прозрачности бюджетной системы дополнен требованием обязательной отчетности участников бюджетного процесса перед гражданами, т. е. органы власти разных уровней обязаны предоставлять населению не только бюджетную отчетность, но и отчетность об итогах расходования бюджетных средств. Тем самым финансовая деятельность органов федеральной власти, власти субъектов Федерации и органов местного самоуправления становится объектом общественных оценки и мониторинга (п. 1 ст. 23 проекта БК РФ). В соответствии с п. 1 ст. 16 проект формируемого бюджета на соответствующий год должен не только быть сбалансированным, но и учитывать реалистичные показатели социально-экономического развития государства.

По мнению Д.Л. Комягина, в проекте необходимо закрепить также иные принципы бюджетного законодательства, успешно используемые в практике зарубежных государств [6]. Например, принцип гармонизации (по опыту ФРГ), согласно которому каждый регион нуждается во взаимодействии как с центром, так и с другими регионами (субъектами); принцип субсидиарности, актуальный в отношении распределения публичных обязательств; принцип приоритета публичных расходов [7]. На наш взгляд, принимая во внимание предназначение принципов права как основополагающих начал, имеет смысл перенести в гл. 1 проекта принципы, закрепленные в гл. 3 
БК РФ, подразделив их на три группы: 1) принципы построения бюджетной системы; 2) принципы организации бюджетного процесса; 3) принципы установления расходов и доходов - подведомственности расходов бюджетов.

Компетенция местных органов власти в бюджетной сфере закреплена в действующем БК РФ в ст. 9, в проекте БК РФ - в ст. 7 и 10. Анализируя обозначенные нормы, можно сделать вывод, что в целом бюджетные полномочия муниципалитетов не претерпели существенных изменений.

Проект нового БК РФ содержит положения, меняющие порядок распределения доходов, поступающих от взимания штрафов. Так, согласно предлагаемым нововведениям доходы от них должны направляться в тот государственный орган, должностное лицо которого наложило соответствующий штраф; штраф должен быть внесен в тот орган, из которого происходит изначальное финансирование нарушенных правоотношений (п. 2 ст. 40 проекта). Предлагаемые поправки направлены на устранение существующих в настоящее время в БК РФ несоответствий распределения доходов, поступающих от взимания штрафов, и неоднозначного толкования и применения анализируемых норм. В то же время коррективы не связаны с полномочиями органов разных уровней власти в рассматриваемой сфере (ст. 46 БК РФ). В результате на практике возникает ситуация, когда у муниципальных образований отсутствует заинтересованность в выявлении правонарушений, поскольку, например, административные штрафы в основном зачисляются только в бюджеты крупных городских поселений.

В разделе III проекта БК РФ закреплены нормы о расходах бюджетов. По сравнению с принятыми в действующем БК РФ положения не претерпели значительных изменений, они лишь были дополнены и конкретизированы. Минфин России предлагает включить новеллы, дающие возможность направить соответствующие бюджетные средства на осуществление государственных программ долгосрочного планирования. Финансирование программ, имеющих в отличие от бюджетного периода более длительные сроки реализации, предлагается разрабатывать на основе принципа проектного финансирования. В случае недостижения результата, заложенного изначально в финансируемой программе, получатели бюджетных ассигнований обязаны выполнить возврат выделенных средств в бюджет (п. 2 и 3 ст. 71 проекта БК РФ).

В проекте БК РФ отменено ограничение применительно к установлению максимальных размеров Резервного фонда президента Российской Федерации (ст. 204 проекта БК РФ), которое в настоящее время составляет 1 \% от расходов федерального бюджета (п. 1 ст. 82 БК РФ). Одновременно предусмотрено снижение объемов резервных фондов органов власти субъектов Федерации и муниципалитетов с 3 до 1 \% (п. 3 ст. 205 проекта БК РФ, п. 3 ст. 81 БК РФ).

В ст. 100 проекта БК РФ в дополнение к дотациям, установленным в целях уравнивания бюджетных ассигнований, предложено ввести дотацию, направленную на поддержку баланса региональных бюджетов, бюджетов на местном уровне.

Нововведением проекта БК РФ является создание дополнительных видов межбюджетных трансфертов - «горизонтальных» субсидий (ст. 106). Они предусмотрены для осуществления взаимопомощи муниципальными образованиями, заключающейся в возможности переводить средства друг другу для фринансирования расходных обязательств. Однако использовать такие дотации могут лишь те муниципалитеты, которые обладают высоким уровнем долговой устойчивости. В настоящее время трансферты направляются исключительно по вертикали: от центра до регионов, от регионов до местных бюджетов.

Один из важнейших способов повышения финансовой обеспеченности разных органов власти Минфин России видит в использовании мер влияния в отношении руководителей регионов и муниципалитетов, которые имеют низкие данные кредитоспособности и не прибегают к мерам регенерации платежеспособности, - вплоть до применения к соответствующим лицам взыскания в виде отстранения от должности. Представляется, что ужесточение и расширение оснований для реализации бюджетных мер принуждения за нарушение бюджетного законодательства в связи с неэффективным и безответственным управлением бюджетными средствами являются необходимым ресурсом гарантии получения денежных средств их конечными адресатами.

Процедура принятия законопроектов о бюджете не изменилась. Вместе с тем в регламент осуществления бюджетного процесса введены некоторые разъяснения и дополнения. В частности, помимо внесения в Госдуму РФ законопроекта о федеральном бюджете Минфин России предложил публиковать сопровождающие документы для общественного изучения на едином портале бюджетной системы, а также на официальном сайте государственных и муниципальных учреждений. При этом использование бумажных документов сохраняется.

В проекте БК РФ внесены изменения в гл. 30 БК РФ о муниципальном финансовом контроле, исключающие из действующего бюджетного законодательства понятие «нецелевое использование бюджетных средств» (п. 1 ст. 306.4 БК РФ). Минфин России предложил привлекать к ответственности администраторов расходов бюджета за совершение действий (бездействий), направленных на увеличение расходов бюджетных средств. 
Проанализировав некоторые положения проекта нового БК РФ, разработанного Минфином России, можно прийти к выводу, что реформы бюджетного законодательства не приведут к существенным изменениям в финансовой деятельности органов местной власти. Следует признать, что сегодня законодательное регулирование полномочий муниципалитетов в финансовой сфере имеет низкую эфффективность. Отсутствие детального управления критериями выделения бюджетных средств на местный уровень приводит к расширению бюджетных прав субъектов в отношении муниципалитетов.

В настоящее время местные бюджеты испытывают острую зависимость от бюджетов федерального центра и соответствующего региона. Так, общий объем муниципальных доходов в 2012 г. составил 46,6 \% (межбюджетных трансфертов) и 53,4 \% (налоговых и неналоговых доходов) [8].

Необходимо признать, что сегодня основная часть направляемых межбюджетных трансфертов является целевой, поэтому местные органы власти никоим образом не могут влиять на распределение субсидий и субвенций и, как следствие, на их расходование. Наблюдается нарушение одного из главнейших принципов местного самоуправления - фринансовой самостоятельности муниципалитетов - в части определения доходов и расходов органов местного самоуправления. Например, в 2012 г. доля нецелевых межбюджетных трансфертов в России составила 29,5 \% [9]. Иные межбюджетные трансферты являются целевыми, что ведет к дефициту фринансовых ресурсов для удовлетворения текущих и неотложных потребностей местных органов власти и тем самым влечет за собой невыполнение необходимых затрат.

Заметим, что в зарубежной литературе финансовая самостоятельность органов местного самоуправления отождествляется с «финансовой безопасностью местной власти». Так, по мнению М. Косек-Вожнар, «безопасность как система обеспечивает соответствующий уровень финансовой независимости местного самоуправления и на практике характеризуется высоким уровнем автономии доходов» [10, р. 11].

Завершая анализ действующего БК РФ и проекта БК РФ в части регулирования фринансовых правоотношений между органами местного самоуправления, с одной стороны, и федеральным центром и органами субъектов Федерации - с другой, следует признать, что проект далек от совершенства, поскольку не отражает всех бюджетных реалий. Он не предполагает фундаментальных корректировок бюджетного законодательства. В текст проекта главным образом включены точечные терминологические изменения (например, рассмотрены понятия «бюджет», «бюджетный процесс», «доходы бюджета») и новые положения (в частности, об инфрормационном обеспечении бюджетных правоотношений, санкционировании бюджетных расходов, особом правовом режиме для муниципальных образований с разными группами долговой устойчивости и т. д.). Между тем формирование и развитие федеративного государства возможно лишь в случае создания в России подлинно действующего законодательства во всех областях жизнедеятельности общества, в первую очередь в бюджетной сфере, отвечающего всем требованиям современной действительности.

\section{Ссылки:}

1. Проект Бюджетного кодекса РФ [Электронный ресурс] : подготовлен Минфином России : не внесен В ГД ФС РФ : текст по состоянию на 8 мая 2015 г. Доступ из справ.-правовой системы «КонсультантПлюс».

2. Бюджетный кодекс РФ от 31 июля 1998 г. № 145-Ф3 // Собрание законодательства РФ. 1998. № 31. Ст. 3823.

3. Поветкина Н.А., Мамцев Г.Ю., Бедоева 3.Н. Новая редакция Бюджетного кодекса Российской Федерации: практические и теоретические вопросы // Журнал российского права. 2015. № 12. С. 157-162.

4. Комягин Д.Л. Некоторые замечания к проекту нового Бюджетного кодекса Российской Федерации [Электронный ресурс]. URL: https://www.hse.ru/data/2015/09/18/1074831896/3амечания\%20к\%20проекту\%20нового\%20Бюджетного\%20кодекса.pdf (дата обращения: 10.08.2017).

5. Горбунова О.Н., Пешкова Х.В., Вершило Т.А. О необходимости совершенствования текста проекта Бюджетного кодекса РФ // Финансовое право. 2016. № 7. С. 37-40.

6. Комягин Д.Л. Указ. соч.

7. Там же.

8. Информация о результатах мониторинга местных бюджетов РФ по состоянию на 1 янв. 2013 г. [Электронный ресурс]. URL: http://www.minfin.ru/common/gen_html/index.php?id=19220\&fld=HTML_MAIN (дата обращения: 10.08.2017).

9. Там же.

10. Kosek-Wojnar M. Problem samodzielności finansowej jednostek samorządu terytorialnego // Zeszyty Naukowe Wyższej Szkoły Ekonomii w Bochni. 2004. No. 2. P. 11.

\section{References:}

Gorbunova, ON, Peshkova, KhV \& Vershilo, TA 2016, 'The necessity to improve the draft of the Budget Code of the Russian Federation', Finansovoye pravo, no. 7, pp. 37-40, (in Russian).

Komyagin, DL 2017, Comments on the draft of the new Budget Code of the Russian Federation, viewed 10 August 2017 , <https://www.hse.ru/data/2015/09/18/1074831896/Замечания\%20к\%20проекту\%20нового\%20Бюджетного\%20кодекса.pdf>, (in Russian).

Kosek-Wojnar, M 2004, 'Problem samodzielności finansowej jednostek samorządu terytorialnego', Zeszyty Naukowe Wyższej Szkoły Ekonomii w Bochni, no. 2, p. 11, (in Polish).

Povetkina, NA, Mamtsev, GYu \& Bedoeva, ZN 2015, 'New edition of the Budget Code of the Russian Federation: practical and theoretical issues', Zhurnal rossiyskogo prava, no. 12, pp. 157-162, (in Russian) 